\title{
O Perspectivismo indígena é somente INDÍGENA? COSMOLOGIA, RELIGIÃO, MEDICINA E POPULAÇÕES RURAIS NA AmAzônia
}

\author{
Raymundo Heraldo Maués ${ }^{1}$
}

\begin{abstract}
RESUMO
0 artigo pretende discutir aspectos da cosmologia e do ethos de populações rurais de três mesorregiões da Amazônia: Nordeste Paraense, Baixo Amazonas e Sudeste Paraense, que têm muito a ver com questões relacionadas à religião e saúde. A discussão é baseada em parte na experiência de trabalho de campo do autor, sobretudo na microrregião do Salgado e na literatura antropológica que aborda o tema em todas essas áreas da Amazônia. Trata-se também de fazer homenagem ao antropólogo João Valentin Wawzyniak, cujo trabalho de pesquisa e cujas publicações representam um avanço importante no conhecimento dessa temática.
\end{abstract}

Palavras-chave: Cosmologia. Amazônia. Populações rurais. Religião. Saúde pública. ${ }^{1}$ Professor do Programa de Pós-Graduação em Ciências Sociais, Universidade Federal do Pará,
Brasil. hmaues@uol.com.br 


\title{
Is THE INDIAN PERSPECTIVISM ONLY INDIAN? COSMOLOGY, RELIGION, MEDICINE AND RURAL POPULLATION IN THE AMAZON
}

\begin{abstract}
This article aims to discuss aspects of cosmology and ethos of three rural populations of the Amazon: Northeastern Pará, Low Amazon and Southeastern Pará, which have a lot to do with questions of religion and health. The discussion is based, in part, on the author's field work experience, particularly in the Salgado micro-region, and also on anthropological literature that addresses the subject in all these areas of the Amazon. The article is also a tribute to the anthropologist João Valentin Wawzyniak, whose research and publications represent an important step forward in the knowledge of that subject.
\end{abstract}

Keywords: Cosmology. Amazon. Rural populations. Religion. Public health.

\section{INTRODUÇÃO}

pergunta do título vem a propósito dos resultados da pesquisa sobre
antropologia da saúde entre habitantes rurais da microrregião do
Tapajós desenvolvida por João Valentin Wawzyniak. Tal pesquisa, como não poderia deixar de ser, precisou desvendar os meandros da cosmologia da população dessa área da Amazônia, incluindo índios e não índios, mas também populações indígenas que reivindicam seu reconhecimento étnico, processo que se tem denominado de etnogênese ${ }^{2}$. Em vários de seus aspectos, a pesquisa de

\footnotetext{
${ }^{2}$ Devo lembrar, inicialmente, que, para Friedrich Nietzsche, o perspectivismo é uma condição fundamental da vida. Está relacionado com a maneira como se vê o mundo, que não é dual, porque não existe um mundo das aparências e outro real (das essências). Mas se relaciona também com a vontade de saber (o desejo de verdade) e com a vontade de potência. Dois aforismos de "A Gaia Ciência" (NIETZSCHE, 2000, p. 189-190) podem ser evocados aqui, parcialmente, por se relacionarem bastante com as questões abordadas neste artigo: "Julgais então que as ciências teriam nascido, julgais que teriam crescido, se não tivesse havido antes estes mágicos [magos], estes alquimistas, astrólogos e feiticeiros que foram primeiro obrigados, por meio da isca de milagres e de promessas, a criar a fome, a sede, o gosto pelas forças escondidas, pelas forças proibidas?" (\$ 300). E, também: "Espero [...] que estejamos hoje longe da ridícula pretensão de decretar que o nosso cantinho é o único de onde se tem o direito de possuir uma perspectiva. Muito pelo contrário, o mundo, para nós, voltou a tornar-se infinito, no sentido em que não lhe podemos recusar a possibilidade de se prestar a uma infinidade de interpretações" (\$ 374). A citação desses aforismos me foi sugerida pela leitura do livro de Marton (2000, p. 215, 222), que os cita com outra tradução. Devo lembrar também que minha citação do $§ 300$ não significa dizer
} 
Wawzyniak retoma a temática de folcloristas desde pelo menos a segunda metade do século XIX (FIGUEIRED0, 2009) e, nos meados do XX, a pesquisa pioneira em antropologia desenvolvida por Charles Wagley e Eduardo Galvão (GALVÃO, 1955; WAGLEY, 1977), que tinha, sobretudo da parte do primeiro, um interesse manifesto na área da saúde pública, num momento em que se davam os primeiros passos para a criação do que hoje é a Fundação SESP, com âmbito de atuação não apenas na Amazônia, mas em todo o território brasileiro.

Muitos outros antropólogos retomaram, na esteira de Wagley e Galvão, esses mesmos estudos, na mesma ou em outras áreas amazônicas. Entretanto, embora os antropólogos pioneiros nesse estudo tivessem interesse nas populações indígenas, com as quais também trabalharam, mesmo eles, assim como os demais que os seguiram na senda de estudos sobre religião e saúde (e na maioria somente preocupados com as populações “caboclas"), não se detiveram no estabelecimento de relações mais próximas entre populações rurais e indígenas (embora sabendo e reconhecendo que os chamados "caboclos" podiam ser vistos como descendentes e possuidores de uma cultura em grande parte influenciada por essa população indígena, especialmente de língua tupi $)^{3}$.

Com o notável desenvolvimento nas pesquisas antropológicas no Brasil e na Amazônia nos últimos anos (desde especialmente a década de 1970), ocorreu também um divórcio entre os trabalhos da chamada "etnologia indígena" e os demais estudos antropológicos (sobre religião, saúde, campesinato, questões urbanas e outras temáticas). Creio poder dizer que, também, grande número de pesquisadores, nas outras áreas de estudo antropológico, solenemente desconhecia a maioria dos estudos de etnologia indígena, mesmo que eles tivessem sido

que concordo com a noção vulgar (que não é de Nietzsche) de que a ciência moderna teve origem na magia. Adoto aqui a formulação de Lévi-Strauss: "Não voltemos à tese vulgar [...], segundo a qual a magia seria uma modalidade tímida e balbuciante de ciência [...]. Mais como uma sombra que antecipa o seu corpo, ela é, num sentido, completa como ele, tão acabada e coerente em sua imaterialidade, quanto o ser sólido por ela simplesmente precedido [...]. Em lugar [...] de opor magia e ciência, melhor seria colocá-las em paralelo, como duas formas de conhecimento, desiguais quanto aos resultados teóricos e práticos [...], mas não pelo gênero de operações mentais que ambas supõem, e que diferem menos em natureza que em função dos tipos de fenômenos a que se aplicam" (LÉVI-STRAUSS, 1970, p. 33-34).

${ }^{3}$ Utilizo a expressão "caboclo", embora esteja consciente de sua conotação pejorativa em vários de seus usos. Entretanto, a expressão é também utilizada na literatura antropológica por diversos autores, inclusive contemporâneos. Para uma discussão bem fundamentada e esclarecedora da questão, cf. Motta-Maués (1989), Lima-Ayres (1999) e Rodrigues (2006). 
desenvolvidos em áreas contíguas àquelas onde realizavam suas pesquisas. Caminhou-se cada vez mais para uma especialização, não só temática, mas que fazia com que dentro da mesma área de pesquisa se desconhecesse às vezes aquilo que nela se estava estudando no campo da etnologia indígena. Nos últimos anos, porém - e felizmente -, essa atitude tem-se modificado. E isto aparece claramente nos trabalhos de pesquisadores mais recentes, como é o caso de Wawzyniak.

Este artigo pretende inicialmente tratar sobre alguns estudos antropológicos (e sociológicos) - desenvolvidos principalmente por pesquisadores brasileiros voltados para o campo da religião e da saúde na Amazônia. Vários desses estudos se concentram nas áreas ou sub-regiões do Baixo Amazonas, do Salgado e da Bragantina (nordeste do Pará). Alguns, embora não preocupados prioritariamente com religião e saúde, não deixam porém de lado a temática, especialmente a religiosa, na sub-região do Carajás (sul do Pará). E também os trabalhos realizados na área do Tapajós (onde se concentraram os estudos de Wawzyniak) e, já no estado do Amazonas, na área dos municípios de Tefé e Coari (onde se localiza a reserva de Mamirauá). Há diversas semelhanças nas manifestações culturais (religiosas, cosmológicas, concepções de doença, práticas de cura etc.) que são comuns a essas áreas, as quais permitem também pensar numa certa identidade cultural entre as populações rurais de todas essas sub-regiões, que serão discutidas neste artigo. A questão nova que se coloca parte do próprio trabalho de Wawzyniak, que aproxima essas concepções e práticas do chamado perspectivismo indígena. Isso será tratado, com mais detalhes, ao longo deste artigo.

\section{Alguns eStudos ANTropológicos SOBRE RELIGIÃO E SAÚDE NA AMAZÔNIA}

Os estudos antropológicos sobre religião e saúde nas áreas rurais da Amazônia têm se concentrado em vários aspectos, com predominância sobre o catolicismo, a pajelança, os hábitos alimentares, as concepções médicas, religiosas e cosmológicas e o tratamento de doenças. Trata-se já de uma produção relativamente extensa, desenvolvida por antropólogos brasileiros e estrangeiros. Não é o caso aqui de fazer um apanhado completo dessa produção, mas desejo referir alguns estudos e aspectos que considero relevantes para as questões abordadas neste artigo. 
Estudou-se, na esteira de Wagley e Galvão, aquilo que este denominou "a religião do caboclo amazônico". Esses estudos foram feitos inicialmente por Napoleão Figueiredo e Anaíza Vergolino e Silva, numa pequena comunidade rural no Alto Cairari, que resultou em livro onde são descritas e analisadas as crenças e práticas do catolicismo e da pajelança de seus habitantes (FIGUEIREDO; SILVA, 1972). 0 primeiro desses autores publicou mais tarde artigo sobre o tema da pajelança denominada "cabocla" - para distingui-la daquela praticada por populações indígenas -, sobre pajelança e catimbó na Região Bragantina (Nordeste do Pará) e retomou a mesma temática em livro e artigo que tratam não somente de pajés, mas também de rezadores e de remédios por eles utilizados, as chamadas puçangas (FIGUEIRED0, 1976, 1979, 1994). Vários outros antropólogos retomaram o tema, em diferentes áreas da Amazônia, como Salles (1967), Maués (1977, 1990, 1995), Lima Ayres (1992), Cravalho (1993, 1998), Maués e Villacorta (2001), Trindade (2007), Cavalcante (2008) e Quintas (2007). Exceto no caso deste último, cujo estudo se desenvolveu em casas de culto urbanas (Belém e Ananindeua) - onde a pajelança aparece com o nome de "pena e maracá", relacionando-se mais fortemente com as práticas religiosas de matriz africana-, todos os outros estudos mostram um padrão de crenças e práticas ritualizadas, bem como de concepções cosmológicas mais amplas que, embora existentes em tempos e lugares distintos da Amazônia, apresentam notável semelhança. É importante mencionar também alguns estudos recentes sobre a alimentação, que se podem incluir no campo da antropologia da saúde, especialmente os de Murrieta (1998, 2001) e de Silva (2007).

Esses estudos indicam que há uma espécie de mescla entre concepções e práticas católicas e do universo da pajelança: santos e encantados (estes, incluídos por Galvão entre o que chama de "visagens") constituem os personagens mais importantes desse mundo mítico. 0 próprio Deus do catolicismo é uma figura distante (deus otiosus, na concepção de Eliade [1957]). Mas não estão ausentes os espíritos (bons e maus, não necessariamente assim chamados), que incluem os "espíritos de luz" e Satanás. Os encantados habitam o fundo das águas (rios, baías, lagos etc.) e as florestas: são por isso também chamados de bichos do fundo ou caruanas (que constituem a grande maioria); mas os encantados da mata se reduzem em alguns lugares apenas a duas entidades: Curupira e Anhanga. Em outros, "os Curupira foram embora", em se tratando de áreas de matas devastadas (SILVA, 1980). 


\section{A mícrorregião do SAlgado: EnCANTAdos E PajéS}

Mais particularmente na microrregião do Salgado (litoral paraense, a nordeste do estado do Pará), onde desenvolvi meu trabalho de campo, o sistema cosmológico - uma bricolage de múltiplas concepções - inclui diferentes planos com seus personagens fundamentais: bem acima (no céu), Deus, anjos, santos, espíritos de luz e "anjinhos" (que morreram crianças). No espaço intermediário, entre o céu e a superfície terrestre, ficam os espíritos maus (uma espécie de demônios, incluindo Satanás) e os espíritos penitentes (que passam por provações, antes de poderem atingir a salvação, no plano superior). Na superfície terrestre habitam os seres humanos (entre o nascimento e a morte), os outros animais e as plantas. No "fundo" - das águas e da terra - fica o lugar do "encante": é a morada dos encantados que, no entanto (e de várias maneiras), relacionam-se com os humanos que moram na superfície. Os encantados são vistos também como seres humanos (não são pensados como espíritos), porque não morreram, mas se encantaram. Os dois mais importantes são o Rei Sebastião e Norato Antônio (Cobra Norato), mas há muitos outros personagens, inclusive princesas, entre as quais se destacam as filhas do Rei Sebastião.

Aqui é necessário detalhar mais um pouco. Os encantados - sendo normalmente invisíveis aos olhos dos outros homens - manifestam- se de três maneiras principais, assumindo em cada caso denominações diferentes. No mar, nas baías, nos lagos e nos rios eles aparecem como animais que normalmente se encontram nesses ambientes: cobras, jacarés, peixes, botos etc. Por isso, são chamados de "bichos do fundo", não sendo fácil distingui-los dos outros animais, não encantados. Outra forma de manifestação que assumem ocorre nas praias e às margens dos rios, das baías e dos lagos: neste caso aparecem sob a forma humana, muitas vezes assumindo a figura de pessoa amiga, um parente próximo, a mulher, o marido, um filho: é quando são mais perigosos, pois, dessa forma, muitas vezes seduzem os seres humanos comuns para levá-los a sua morada, o encante. Outras vezes, quando assim aparecem - como na lenda da princesa, filha do Rei Sebastião, na ilha de Maiandeua -, manifestam-se a pescadores para que consigam, mediante um ritual específico, libertá-los do encantamento; no caso da lenda da princesa, nela encontramos nitidamente um sentido messiânico ou escatológicót.

\footnotetext{
${ }^{4} \mathrm{~A}$ lenda - que ouvi em várias versões - narra a história de um jovem pescador que, sozinho nessa praia, há muitos anos atrás, encontra uma linda mulher, loura e de olhos azuis, que se
} 
A terceira forma de manifestação, muito comum, é quando, permanecendo invisíveis, incorporam-se num pajé ou numa pessoa comum de quem se agradam e que desejam tornar pajé. Aqui temos o xamanismo - essa manifestação mística universal - praticado por pajés amazônicos não indígenas, que desperta tanta atenção dos pesquisadores e tem sido estudado por vários estudiosos na Amazônia.

Há também formas de manifestação de encantados talvez menos comuns, sobre as quais recebi poucas notícias e que, geralmente, dizem respeito ao passado ou a lugares mais distantes. Mas, com uma exceção: as manifestações da Curupira e da Anhanga. Esses encantados no litoral paraense são referidos no feminino, mas na literatura nacional, da qual são figuras tão presentes, aparecem usualmente no masculino. Tal ambiguidade se explica talvez pela própria ambiguidade com que são concebidos na microrregião do Salgado: pensados como "maciços", não possuem o ânus nem órgãos sexuais. Aparecem a caçadores que cometem infrações contra o ambiente da floresta, caçando um número muito grande de animais, ou perseguindo sempre o mesmo animal, ou cometendo faltas que poderíamos classificar como prejudiciais ao ambiente natural. Metamorfoseados como animais atraem o mau caçador para uma cilada, fazendo-o perder-se na mata. Vale dizer que alguns dos encantados ou bichos do fundo - as chamadas mães dos rios - também castigam as pessoas que prejudicam os cursos d'água,

identifica como a filha encantada do rei Sebastião. A princesa propõe que ele a desencante: terá como prêmio casar-se com ela. Para isso precisará voltar à meia noite com uma faca virgem. Ele então verá três ondas: a primeira é o próprio rei; a segunda, a rainha; a terceira, a princesa. Esta aparecerá sob a forma de cobra grande. Para desencantá-la terá de cortar seu couro com a faca, provocando sangue. Acontece que, tendo feito tudo como lhe foi dito, no momento em que vê aquela imensa cobra, fica apavorado e foge. Ainda ouve o lamento: "Ah ingrato, redobraste meus encantos". Chega a sua casa com muita febre e só piora, a despeito de todos os tratamentos do pajé que 0 atende. Seu castigo é a morte. A lenda também diz que, se o rei se desencantar, todas as cidades próximas irão para o fundo, invertendo-se a situação atual do mundo: as cidades dos encantados emergirão à superfície, instaurando-se o reinado de D. Sebastião sobre a terra. Trata-se, claramente, de um mito inspirado no tão conhecido sebastianismo português. Vale lembrar que a ilha de Maiandeua é hoje um importante local de turismo, cuja praia principal tem o nome de Algodoal. Logo em seguida vêm as praias da Princesa, Fortaleza e Mocooca. No interior da ilha existe o Lago da Princesa, muito frequentado também por turistas. Essa ilha é pensada como uma das quatro moradas do Rei Sebastião, no litoral entre Belém e São Luís. As outras são a ilha de Fortaleza, onde fica a pedra do rei Sabá e o coração da Princesa; a pedra do rio Gurupi, na foz desse rio, que separa o Pará do Maranhão; e, já no litoral do Maranhão, a ilha dos Lençóis, a principal morada do mesmo rei. 
aplicando-lhes o que é conhecido como "flechada de bicho", uma doença que só pode ser curada pelo pajé.

Duas situações, no entanto, foram sempre narradas no passado em lugares distantes, não sendo nunca possível identificar as vítimas ou sujeitos nos quais se manifestaram tais fenômenos. Não encontrei na microrregião do Salgado nenhum "filho de boto", embora essas estórias sejam contadas tão frequentemente na literatura de ficção ou nas cidades mais importantes a respeito de mulheres amazônicas interioranas e alguns de seus filhos. 0 tema também se presta à ficção literária e cinematográfica. Mas a lenda sobre o boto que se transforma em belo rapaz para seduzir as mulheres existe também no Salgado, com uma variante, no entanto, que foi aquela que sempre ouvi de meus interlocutores: o boto age como uma espécie de vampiro, ao manter relações sexuais com a mulher seduzida, pois lhe chupa o sangue: ela definha, fica "amarela" (anêmica) e, se o processo não for interrompido, passando a ser tratada por um pajé, acabará morrendo. Aqui creio ser possível fazer analogia com situações descritas nos processos inquisitoriais portugueses pesquisados, por exemplo, por Luis Mott (MOTT, 1985). Nesses processos são descritas relações sexuais de homens e mulheres com íncubos e súcubos, demônios disfarçados cuja identidade era possível descobrir por seus parceiros humanos, já que possuíam um orifício nas costas. Curiosamente, nas lendas amazônicas, um orifício é mantido pelo boto transformado em gente, que é por onde ele respira quando está nas águas. A ambiguidade do boto, que é mamífero em forma de peixe, pode muito bem ser responsável pelos mitos que são narrados a seu respeito 5 .

A outra situação é aquela que acontece com os chamados pajés "sacacas". Eles são referidos por Galvão e Wagley e aparecem nos relatos que obtive na microrregião do Salgado, mas sempre localizados no passado. São pajés que, ao invés do voo xamânico da tradição siberiana descrita por Eliade (2002), realizam a "viagem" pelo fundo, tal como o fez o famoso profeta no ventre da "baleia": são os Jonas amazônicos, só que viajam pelo fundo sem servir-se do ventre de nenhum peixe ${ }^{6}$. Mergulham nas águas e vão conviver com os encantados no fundo, com

\footnotetext{
${ }^{5}$ Um dos mais importantes estudos publicados sobre o boto é o livro da pesquisadora americana Candace Slater (1994). Sobre o mesmo tema, mas, infelizmente, sem incorporar as contribuições de Slater, cf. também Maués (2008).

${ }^{6}$ Vale lembrar aqui os simbolismos associados à aventura do profeta Jonas que, num certo sentido, morre e ressuscita: ele é comido por um peixe, mas cuspido na praia ainda vivo. No ventre do peixe,
} 
quem aprendem novas técnicas e remédios. Só não podem comer nada do que lhes é oferecido, caso contrário tornar-se-ão encantados e não poderão mais voltar - como pajés ou curadores - para a superfície. Este é o grande risco que correm, pela potencialização de seus poderes. Jonas/xamã/profeta ganhou novos poderes e forças a viajar no ventre da baleia para perder o medo e poder pregar de forma mais eficaz em Nínive, mas os pajés sacacas amazônicos recebem diretamente dos bichos do fundo ou encantados as receitas e técnicas mais poderosas para curar seus pacientes. Ambos correram riscos, mas saíram fortalecidos da experiência. Ao invés do "voo xamânico", alguns xamãs amazônicos caboclos realizam pois o mergulho xamânico, que é outra forma de viagem, pelo fundo das águas.

\section{A MESORREGIÃo do SUDESTE PARAENSE E A BESTA-FERA}

Passemos, porém, agora a outra área da Amazônia, que fica não mais no nordeste, mas no sul do Pará. Foi lá que o antropólogo Otávio Velho fez sua pesquisa de mestrado, sob a orientação de Roberto Cardoso de Oliveira, para estudar o campesinato dessa área de fronteira, grande parte dele constituído por migrantes nordestinos. Tratava-se também de contraponto aos estudos já desenvolvidos ou em progresso de outros alunos de Cardoso de Oliveira entre as populações indígenas da mesma área, atingidas por essa frente de expansão agrária no território paraense, onde a cidade mais importante era Marabá e por onde passaria a estrada Transamazônica, projeto do governo militar para, supostamente, permitir 0 "povoamento" de uma terra desabitada7. Foi neste lugar que Otávio Velho ouviu as estórias sobre a Besta Fera, que são referidas em sua dissertação e no livro dela

ele pode meditar e reformular suas ideias; ao ser restituído à vida, na praia, é um homem novo que, de certa forma, ressuscitou. Mas, ao mesmo tempo, esse relato bíblico permite criar o símbolo dos primeiros cristãos, no antigo Império Romano: o símbolo do peixe.

${ }^{7}$ A professora Ivonete Coutinho da Silva, em sua tese de doutorado, nos fala da "invenção da Transamazônica", cuja ideia surgiu no final dos anos 1960 e que foi criada em uma área já habitada por índios, seringueiros, pequenos e grandes comerciantes, marreteiros e fazendeiros. Foi, no entanto, tratada pelo governo militar como uma estrada que estava sendo aberta num "vazio de homens e mulheres, terra a ser conquistada e colonizada". Entre outras histórias de violência praticadas na sua implantação, ainda se ouvem, nos dias atuais, "fragmentos de relatos sussurrados, a respeito do genocídio cometido contra os índios que povoavam o antigo município de Altamira", os quais eram "amarrados a tratores que avançavam sobre a selva" (SILVA, 2008, p. 32).

O Perspectivismo Indígena é Somente IndíGena?...

R. H. MAUÉS 
resultante, mas cujo nome aparece com destaque em livro mais tarde publicado pelo mesmo autor, depois de reflexão bem mais prolongada e madura (VELHO, 1981, 1995).

Trata-se de personagem que não encontrei no nordeste paraense, mesmo que essa região seja também influenciada por nordestinos, especialmente aqueles vindos do Maranhão. Uma possível explicação para isso pode estar no fato de que esses migrantes, alguns deles familiarizados com a pajelança maranhense (que recebe maiores influências da Casa das Minas), são, sobretudo, moradores do litoral. Mas, não é o caso de insistir nesse ponto. 0 que desejo ressaltar é que a figura bíblica da Besta Fera está mais presente no Nordeste e, talvez, mais fortemente ainda, no sertão nordestino. Ela aparece, por exemplo, em trabalhos de antropólogos que estudaram o campesinato nessa região, como, por exemplo, Regina Novaes:

Embora os trabalhadores evangelizados insistam que foi somente através dos agentes de pastoral, ligados à Igreja da Libertação, que eles tiveram acesso à Bíblia, sabemos que certos fatos e histórias da Bíblia sempre foram conhecidos e citados entre eles. Na literatura de cordel produzida no Nordeste, por exemplo, recorrentemente há alusões a personagens bíblicos. Uma, muito presente, é a Besta Fera [...]. No mundo da política também a Besta Fera ocupou lugares distintos e veiculou avaliações díspares. Nas Ligas Camponesas dos anos 60, dizia-se "o latifúndio é a Besta" [...]. [E] após o Golpe Militar [...], periferias pobres onde moravam trabalhadores expulsos de engenhos e usinas foram chamadas de Rabo da Besta [...]. A Besta continuava sendo relacionada ao "latifúndio" e o povoado (resultado da expulsão dos trabalhadores) sua abominável obra? Ou se, como cheguei a ouvir anos depois, o Rabo da Besta seria obra dos "comunistas" que vieram de fora "para organizar os camponeses" e "prometeram leis que não vieram"? [...] Contudo, [...] também os patrões usaram publicamente esta mesma imagem para definir os "falsos profetas", isto é, aqueles que apareciam como padres e bispos, seduziam os trabalhadores com seus ensinamentos, mas eram - de fato - "Bestas do Apocalipse" [...]. Enfim, e paradoxalmente, o que talvez garanta um lado "classista" da metáfora da Besta Fera é o fato da sua imagem perpassar verticalmente 0 imaginário de segmentos diversos de uma sociedade também dividida em classes. A personagem pertence - de maneira peculiar mas simultânea - à cultura popular e à erudita. E são justamente 
possibilidades díspares, mas que se apoiam em dúvidas e certezas socialmente partilháveis, que tornam vivos os símbolos (NOVAES, 1997, p. 209-211).

Antes de voltar às formulações mais extensas de Otávio Velho creio ser útil mencionar algumas das observações do sociólogo José de Souza Martins em um de seus artigos. Tratando de movimentos milenaristas na Amazônia, esse autor se refere ao joaquimismo, doutrina fundada por Gioacchino Da Fiore, monge que viveu na Calábria no século XII e que pregava o advento do Tempo do Espírito Santo, no qual haveria de existir uma época de justiça, fraternidade e fartura: "um tempo de libertação". A isso se associa a ideia apocalíptica da Besta Fera:

Têm sido muito fortes na região as representações do mal que aflige os camponeses ameaçados de expulsão da terra pelos grandes proprietários epelas grandes companhias na figura da Besta-fera apocalíptica. Frequentemente, os diferentes, os de fora, os antagônicos, são considerados "correios da Besta", enviados da Besta. A Besta é também a configuração do dinheiro nesse universo marcado pelo grande fluxo do capital, agente reconhecido das violências contra esses camponeses [...]. Também entre as populações indígenas na situação de contato têm ocorrido movimentos messiânicos no período relativamente recente, como entre os Tükuna, os RamkokamekraCanela, os Krahô e diferentes grupos Tupi. Frequentemente, concepções messiânicas relacionadas com a proximidade do branco e a desorganização do mundo tribal que ela acarreta. Baseiam-se, quase sempre, na alteridade que o branco representa, na desigualdade de forças no confronto entre índios e brancos. Se são tentativas de incorporar os brancos nas suas referências míticas, são também construções míticas da inversão possível dessas relações, como ocorreu no messianismo Krahô (MARTINS, 1996, p. 55).

Otávio Velho, por sua vez, trata de categorias que incluem cativeiro (também uma categoria bíblica), escravidão (que na Bíblia se aplica aos judeus, tanto no Egito como na Babilônia), tudo isso transportado para a Amazônia do século XX na relação dos camponeses com o capitalismo, o autoritarismo, a expropriação, a proletarização e outras formas de violência. E mostra como essas

\footnotetext{
${ }^{8}$ Regina Novaes, em nota ao Capítulo 13 de seu livro, menciona, além de Otávio Velho, outros autores que "registram a presença significativa da Besta Fera no imaginário dos trabalhadores do campo brasileiro": Martins (1981), Musumeci (1988), Novaes (1985), Sigaud (1979) e Soares (1982). Desses autores, é José de Souza Martins, além de Otávio Velho, o que registra essa concepção de origem bíblica também na Amazônia.
} 
concepções resultam de um conhecimento bíblico não suposto por aqueles que não estão familiarizados com essa população rural.

Observo, porém, que em minha experiência no nordeste do Pará, lidando com camponeses e pescadores artesanais, numa das áreas de colonização mais antigas da Amazônia (ao contrário do sul do Pará, de colonização bem mais recente), nunca encontrei, como disse, a noção de Besta Fera. Talvez ela seja mais própria de regiões de luta camponesa, onde o latifúndio ameaça constantemente os trabalhadores e pequenos proprietários, ao contrário do que ocorre na microrregião do Salgado paraense, onde predomina o minifúndio. Nessa área, porém, encontrei sempre algum conhecimento bíblico, que certamente resulta de um catolicismo ali presente por séculos, mas também, e talvez de forma mais acentuada, desde os primeiros anos do século XX, em razão da influência conspícua dos pentecostais.

Por outro lado, Otávio Velho registra, também, a presença no sul do Pará de uma noção presente em várias culturas - o que (acrescento) é ilustrado pela presença de seu nome em diferentes línguas ocidentais - que é o mau-olhado (mal de ojo, evil eye, manvais oeil, malocchio, etc.). Depois de tratar, a partir de uma reflexão inspirada na obra de Paul Ricoeur, especialmente "0 Simbolismo do Mal" e "0 Conflito das Interpretações", do preto como símbolo do mal, do mal como mácula ou impureza (diferentemente associado ao homem e à mulher), ele fala do mau-olhado:

Por último, nessa linha de raciocínio, chamaríamos atenção para a distinção, que registramos em nosso trabalho de campo, entre mau-olhado e olho mau ou ruim. Nessa distinção [...] a questão do mal aparece explicitamente. No caso do mau-olhado, os efeitos dependem de um desejo e/ou emoção (admiração extremada, inveja). No segundo caso, do olho ruim, os efeitos (que podem ser similares aos do mau-olhado) são função de atributos de que certas pessoas são dotadas independentemente de sua própria vontade (VELHO, 1995, p. 23, grifo do autor).

E, depois de dizer que neste último caso "o mal pode até se tornar útil, o que parece estar longe de uma concepção reificada ou maniqueísta", como no exemplo de mulheres que gostam de "lavar roupa no rio com uma mulher de olho ruim para ficarem protegidas contra cobras”, acrescenta:

Reconhece-se, portanto, a diferença entre o olho (ontológico, por assim dizer; externo) e o olhar (existencial, interno). E aqui, muito claramente, ambos 
se referindo ao mal, e como que apontando para o seu caráter complexo: pois justamente em sua face mais ontológica, externa e substantiva ele não se opõe de modo absoluto ao bem, mas pode antes ser posto a seu serviço. No caso das cobras (exemplo que os informantes privilegiam), remetendo-se também por aí, no plano simbólico, à Bíblia e à questão do mal (VELHO, 1995, p. 23, grifo do autor).

No nordeste paraense encontrei algo semelhante, embora com pequena variação e um conteúdo mais rico: quatro formas de mau-olhado (de gente, de bicho, de sol e de lua). Os dois últimos podem ser pensados como pertencentes a uma só categoria inclusiva, o que os interlocutores chamavam de "astros"; tratava-se no entanto de uma forma de "doença" que acometia crianças pequenas e tinha menor gravidade. Mais perigosos são o mau-olhado de gente e o de bicho (encantados, que podem manifestar-se sob a forma de animais). Mas há uma diferença importante entre mau-olhado, motivado por pessoas que têm o "olho ruim", capaz de provocar doença em outras de ambos os sexos e de todas as idades (ou "secar" plantações), e o quebranto, que não é provocado pelo olho, mas pela "admiração", que resulta da inveja e se expressa através de elogios, geralmente dirigidos a uma criança, exaltando sua beleza. Neste caso, o que "corta" o efeito da admiração e suas consequências maléficas é a expressão usualmente empregada por quem não deseja prejudicar a criança: "benza Deus".

Aqui temos de alguma forma a famosa distinção de Evans-Pritchard (1937) quando assinala a diferença feita pelos Azande entre witchcaft (bruxaria) e sorcery (feitiçaria), a primeira provocada por uma espécie de má qualidade intrínseca possuída pelo agente (o bruxo ou a bruxa) - seja intencional ou não intencional - e, a segunda, por algo que é sempre intencional, mas decorre não de uma qualidade intrínseca do feiticeiro e sim de expressões ou atos que, deliberadamente, provocam o mal (sorcery, feitiçaria), como por exemplo a manipulação de substâncias externas ao corpo do feiticeiro. Também a mulher grávida ou menstruada pode praticar o mal, sem intenção (embora também desejando provocá-lo), a transmitir panema ao caçador ou pescador comendo sua "embiara" (o produto da caça ou da pesca), ou, no caso da grávida, matando a certa distância, sem tocá-las, cobras que se atravessem em seu caminho. Mais claramente, temos nessa área, como entre os Azande e em outras partes do mundo (em todas elas?), formas mais características de feitiçaria (sorcery), que é o ato 
de provocar o mal através da manipulação de substâncias externas ao corpo do feiticeiro ou da feiticeira.

Mas tudo isso nos remete a outras situações, no sul do Pará e em outras áreas. José de Souza Martins, em nota, referindo-se aos enviados da Besta Fera, refere-se ao Capa-Verde, a partir de um cordel que menciona a figura do Padre Cícero:

De um folheto manuscrito recolhido no norte do Mato Grosso, cópia de folheto de cordel impresso, sob o título de A Voz do Padre Cícero, consta a seguinte expressiva estrofe relativa a esse assunto: "São anjos do diabo/Que chegam no fim da era/Fazendo tanto milagre/Que todo mundo os venera/Saciando fome e sede/São igual ao capa verde/Correios da Besta-Fera". Margarida Maria Moura alertou-me para a possibilidade de que o Capa Verde seja a reconstrução mítica e humanizada de algo parecido com o Livro da Capa Verde, em que eram anotados os débitos fiscais dos mineradores no Distrito Diamantino, em Minas Gerais, fonte e motivo de severíssima repressão por parte dos funcionários da Coroa. No Nordeste, no estado da Paraíba, Costa também encontrou o mito do Capa Verde entre trabalhadores do sisal. Nesse caso, porém, eles entendem que o próprio sisal é 0 Capa Verde [...]. Em São Domingos das Latas, no Pará, em 1969, o antropólogo que ali chegou para realizar sua pesquisa foi considerado enviado da Besta (MARTINS, 1996, p. 40).

Estaúltima observação refere-se a Otávio Velho, que nos diz, para em seguida citar o Apocalipse: "Uma das figuras mais acionadas no contexto da desconfiança é derivada da Besta-Fera - trata-se de seu enviado. Vimos pessoalmente, em momentos e lugares diferentes, como até mesmo o pesquisador pode ser tomado como enviado da Besta-Fera [...]". Ou mesmo um entrevistador do IBGE, que coletava dados para o Estudo Nacional de Despesas Familiares (ENDEF), na região de Marabá: "Em ambos os casos, foi acentuado pelos informantes o fato de o pesquisador vir de fora, instalar-se no local e fazer perguntas; acrescentando-se, no caso do ENDEF, o fato extraordinário de pesar tudo o que as pessoas comiam" (VELHO, 1995, p. 30). A citação do Apocalipse é do capítulo 13, versículos 14-15, que se refere à sedução dos habitantes da terra, ao incitá-los a produzir imagens da Besta. E que "faz também com que todos, pequenos e grandes, ricos e pobres, livres e escravos recebam uma marca na mão direita ou na fronte, para que ninguém 
possa comprar ou vender se não tiver a marca, o nome da Besta ou o número do seu nome" (apud VELHO, 1995, p. 30).

\section{A mesorregião do Baixo Amazonas: a Curupira COMO BESTA-FERA, “ENGERADA” NO IBAMA?}

Essas considerações, a partir de trabalhos de pesquisa, sobretudo referentes ao sul do Pará, me permitem passar, agora, para outra área amazônica, no oeste do Pará, a mesorregião do Baixo Amazonas e, mais particularmente, as microrregiões de Óbidos e Santarém, também bastante estudadas por antropólogos (CRAVALHO, 1993, 1998; HARRIS, 2000, 2006; SILVA, 1980; WAWZYNIAK, 2003, 2004, 2009, 2010, 2011).

Mark Cravalho, em sua dissertação de doutorado e em capítulo de livro mais tarde publicado em português, conta a história de um xamã que virou "encantado". Tratava-se de um homem doente de epilepsia, que costumava beber em excesso e que transitava entre o pentecostalismo e o catolicismo; quando católico, era xamã (pajé) e, quando membro da Assembleia de Deus, abandonava o xamanismo e a bebida. Um dia, saiu para pescar num lago e não voltou. Difundiu-se a história de que ele teria sido levado para o fundo pelos encantados e se tornado um deles (CRAVALHO, 1998).

Mark Harris, em seu belo livro - Life on the Amazon - nos fala sobre aspectos da vida religiosa dos habitantes dessa área amazônica:

Separados dos santos que habitam o domínio espiritual, o mundo do divino é habitado por vários seres como os encantados, mães de bicho, bichos visagentos, visagens e várias criaturas folclóricas, tais como a curupira e a cobra grande. Trata-se de seres que podem encantar as pessoas reais e têm muitas vezes intenções malévolas [...]. Esses encantados (nome genérico para todos eles) vivem no meio ambiente e são estreitamente associados aos vários domínios ecológicos, o rio, o igarapé (stream), uma cavidade profunda no leito do rio, o lago e a floresta, e uma cidade encantada no fundo do rio. Mesmo que alguns desses seres sejam geralmente invisíveis, eles são reais em razão de suas ligações com 0 ambiente e ocasionalmente se manifestam aos seres humanos. Alguns animais são também considerados como encantados. 0 mais comum entre eles é o boto vermelho ${ }^{9}$ (rose-coloured dolphin), que

${ }^{9}$ Utilizo a expressão "boto vermelho" nesta tradução por ser a que é utilizada comumente 
pode transformar-se em ser humano quando o deseja. Além disso, os animais têm mães, mães do bicho, que os protegem da interferência humana. As pessoas tendem a respeitar as mães do bicho, evitando sua raiva, que pode ser provocada por mulheres menstruadas, excesso de atividade de pesca e de caça, ou falar mal dessas entidades quando elas estão escutando. Isso tem levado alguns comentaristas a argumentar que existe uma ética em relação ao meio ambiente e aos animais que habitam as áreas rurais (HARRIS, 2000, p. 72 , tradução nossa $)^{10}$.

Tatiana Lins e Silva, em sua dissertação de mestrado, nos diz que "os Curupira foram embora", em área tapajônica onde se processou, ainda nos anos 1970, forte processo de desmatamento (SILVA, 1980). Parcialmente tendo a concordar com ela, quando considero meus dados sobre a microrregião do Salgado, cuja coleta começou a ser feita no mesmo período ${ }^{11}$. No Salgado esse desmatamento é secular, por ser área de colonização muito antiga, desde o século XVII, tendo se tornado - juntamente com a bragantina, também no nordeste paraense - a região de maior densidade populacional da Amazônia, além de uma área onde predomina (como foi dito) o minifúndio. São menos frequentes as referências aos únicos encantados da mata ali presentes: a Curupira e a Anhanga. Isso, porém, pelo que encontro na literatura, não acontece da mesma forma no Tapajós. Por outro lado, nessa região, os nomes desses encantados podem ditos nos dois gêneros. Mas, João Valentin Wawzyniak tem outras razões para (pelo menos em parte) discordar de Lins e Silva. E aqui começo a tratar de um dos pontos fulcrais deste artigo. Isto tem a ver com uma categoria nativa que aparentemente

pela população rural amazônica (pelo menos no nordeste paraense), diferentemente da que é ultimamente divulgada pela imprensa brasileira que usa a denominação "cor de rosa", a partir da visita do francês Jacques Cousteau, que assim denominou essa variedade de boto, talvez sem atenção às tradições locais. Note-se que o próprio Harris utiliza a expressão que pode ser traduzida por "cor de rosa".

${ }^{10}$ Mark Harris cita, também em apoio de suas afirmações, os trabalhos de Galvão (1955), Lima Ayres (1992) e Smith (1982).

${ }^{11}$ Participamos do mesmo projeto de pesquisa, proposto à FINEP por Roberto Cardoso de Oliveira e Roberto Da Matta, em meados dos anos 1970, que se destinava a investigar, em várias áreas do Brasil, os "Hábitos e Ideologias Alimentares em Grupos Sociais de Baixa Renda", cuja execução foi coordenada, no Museu Nacional, por Otávio Velho e, na UnB, por Klaas Woortmann. Este projeto permitiu a pesquisa de campo de vários estudantes de mestrado do PPGAS/MN e do PPGAS/UnB e resultou em vários estudos em quase todas as regiões do Brasil (Norte, Nordeste, Cento-Oeste e Sudeste). 0 relatório final, englobando todas as pesquisas realizadas, encontra-se até hoje na página da web do PPGAS da UnB (WOORTMANN, 1978). 
não existe no nordeste paraense, mas que é fundamental no Tapajós: a palavra engerar, que significa transformar:

Há relatos indicando que também objetos inanimados se transformam em seres animados, como pode ser constatado na história relatada por um morador de uma das comunidades sobre o caso de uma flecha a ele presenteada por um cunhado. Segundo ele, ela se transformou numa cobra e tentou matá-lo. Interpreto que esses ribeirinhos interpretam também o IBAMA como uma forma assumida pela/o Curupira. Tal associação decorre de uma série de analogias do comportamento das duas entidades, o que os leva a adotarem uma atitude de suspeita em relação ao instituto, uma vez que ele pode ser uma aparência assumida pelo "bicho". Nesse sentido, um órgão público federal apresenta-se como o "engeramento" de um ser com poderes de encantamento, diante do qual é conveniente assumir uma atitude de respeito e suspeita. Deste modo, tudo indica que o pensamento que postula a potencialidade de transformação dos seres abrange também outras agências. Se verdadeira essa interpretação, ela contradiz Lins e Silva (1980), que em estudo realizado no planalto santareno indica o desaparecimento das/dos Curupiras como consequência do desmatamento, por não disporem mais do espaço onde habitavam. Contudo, uma outra explicação pode ser possível, ou seja, a de que tenham "se engerado" em outra qualidade de ser (WAWZYNIAK, 2003, p. 44).

Seria então possível pensar que na Amazônia tapajônica a/o Curupira cumpre as funções da Besta Fera no imaginário das populações rurais? Em seu artigo, Wawzyniak faz considerações sobre "um sistema cosmológico que postula a permutabilidade dos seres entre si - homens, animais e demiurgos" e relaciona a categoria "engerar" ao "mau-olhado de bicho". Pois é através do olhar do bicho, isto é, do ser mítico que tem poder de engerar, que os humanos são afetados por mudanças no seu estado e mesmo transformações mais radicais. Isto também permite fazer ligação com as observações de José de Souza Martins, comentadas acima e, mais particularmente, com as de Otávio Velho que, embora não identificando o mau-olhado de bicho, estabelece uma relação metafórica entre mau-olhado e Besta Fera. Teríamos então, no oeste do Pará, na microrregião de Santarém, uma transformação da Besta Fera em Curupira? Dois representantes do mal "se engerando" um no outro? Observo, porém, que esta aproximação de minha parte pode ser exagerada (embora tentadora), pois, considerando meus dados na microrregião do Salgado sei que a população rural também lida com a 
ideia do demônio (Satanás), com várias denominações, que aparece em diversas circunstâncias, entre elas quando alguém está prestes a encontrar um "tesouro enterrado" $"$.

Mas Wawzyniak vai mais longe, na discussão do "sistema cosmológico que postula a permutabilidade dos seres entre si”. Ele o relaciona ao perspectivismo indígena formulado por Eduardo Viveiros de Castro, adotando uma noção de cosmologia que empresta de Kaj Arhem (também citado por Viveiros de Castro) como "constructo cultural holístico composto por um conjunto de representações e saberes que orientam os indivíduos, moral e existencialmente, na sua interação com a natureza" (WAWZYNIAK, 2003, p. 41) ${ }^{13}$. Evidentemente que essa cosmologia construída pelas populações rurais da Amazônia (e pelos migrantes que para ela vêm, de várias partes do Brasil, mas em grande medida do Nordeste) não corresponde inteiramente (e nem poderia ser de outra forma) com a dos índios de origem tupi (nem de qualquer outra origem) na Amazônia. Há variações em torno de temas comuns mesmo na Amazônia, em diferentes áreas dessa enorme região, bem como dentro da mesma área.

Mas a questão não poderia ser colocada em termos bem mais amplos, como indica o próprio Wawzyniak? Uma nota de rodapé introduzida por ele em sua comunicação apresentada em Belém, durante a $27^{a}$ Reunião Brasileira de Antropologia ${ }^{14}$, permite-nos ir mais além nessa discussão:

Ao contrário do que sugerem certas concepções que a sociedade ocidental faz dela mesma, que foram inclusive expressas por Da Matta, não há oposição entre técnica e crenças sobrenaturais. Mais ainda, se lembrarmos que uma ética protestante parece estar no âmago da construção do capitalismo, a dissociação entre crença e técnica não seria válida nem mesmo para a sociedade ocidental (WAWZYNIAK, 2010, p. 4).

\footnotetext{
${ }^{12}$ Segundo as crenças locais esses tesouros teriam sido enterrados pelos cabanos, revoltosos paraenses do período regencial. Mais ainda, quem enterra um tesouro e morre sem resgatá-lo não pode obter a salvação e, no sistema cosmológico local, figa vagando no espaço entre a terra e o céu. 0 diabo aparece para evitar que o tesouro seja desenterrado, a fim de impedir que aquele espírito ou alma penada encontre a salvação.

${ }^{13}$ Não se deve esquecer de associar ao perspectivismo indígena as ex-alunas de Viveiros de Castro, Aparecida Vilaça e Tânia Stolze Lima, que contribuíram para sua formulação. 0 artigo mais importante que lançou ao mundo essa importante teoria foi assinado por Viveiros de Castro (1998) e devo assinalar que, nele, o autor cita também os trabalhos e as contribuições de suas ex-alunas. ${ }^{14}$ Publicado neste volume (nota das organizadoras).
} 
Sem tentar estender o tema além do que é cabível neste artigo, sugiro que se considere o fato de que, na Amazônia, para a grande maioria de sua população, o padrão usual de pensar o mundo é muito menos dicotômico - muito mais holístico, para usar a expressão de Arhem -, do que aquilo que é predominante pelo menos nas camadas intelectualizadas da sociedade ocidental.

Em outro artigo, apresentado originalmente na $5^{\text {a }}$ Reunião de Antropologia do Mercosul, em Florianópolis, no ano de 2003, e mais tarde publicado em periódico, Wawzyniak aprofunda esta temática, tratando das relações dos moradores da Flona do Tapajós com o IBAMA, mostrando como a "engeração" (transformação) deste órgão na/no Curupira lhes permitiu lidar com maior familiaridade com essa nova situação política, colocando-a num campo semântico com o qual estão habituados, o que lhes facilitava a interpretação e avaliação de posturas e discursos ambíguos desse órgão federal, ao mesmo tempo que lhes facilitava a criação de estratégias para lidar com o mesmo, diante das novas conjunturas que lhes eram apresentadas (WAWZYNIAK, 2004).

A questão cosmológica aparece de novo em seu artigo sobre os Agentes Comunitários de Saúde (ACSs). Logo na primeira página do artigo o autor nos coloca sua proposta:

Esses ACSs exercem suas atividades cotidianas guiando-se por uma cosmologia segundo a qual não existe dicotomia ou antagonismo entre as dimensões naturais e sobrenaturais e na qual é possivel a intervenção de seres sobrenaturais sobre a ordem natural. Sua cosmologia também admite o reconhecimento dos elementos do meio como possuindo poder de encantamento e a possibilidade de alguns seres se transformarem em outros. A relação com estes seres, "bichos", é possível porque os concebem como dotados de atributos humanos, tanto que a relação é tratada como sendo entre pessoas, entidades morais - em algumas situações, classificadas como parentes - com as quais são estabelecidas relações sociais (WAWZYNIAK, 2009, p. 59).

A análise da atuação desses agentes leva em conta o fato de que constituem uma espécie de brokers, vivendo entre dois mundos, o de sua comunidade (alguns são índios, outros não, alguns são pajés, benzedores, outros não; são pessoas de ambos os sexos), mas partilham de um pensamento cosmológico comum (ou muito próximo) e, de qualquer forma, diferente daquele dos agentes de saúde formados de acordo com os critérios da biomedicina, sobretudo os médicos. 
Mesmo o projeto de saúde implementado na área por uma ONG muito conhecida - Saúde e Alegria -, que difunde a ideia de respeito e consideração pelas tradições locais, na prática não age assim, conforme o autor. Se de um lado os ACSs têm de cumprir as normas preenchendo relatórios que deem conta de sua tarefa, eles não podem esquecer suas ligações pessoais, seus compromissos comunitários, seu modo de pensar que é diferente. Isso leva a muitas tensões e conflitos. Mas, ao mesmo tempo, são eles que estabelecem a ligação entre o sistema oficial de saúde e as comunidades da Flona do Tapajós, até mesmo indicando quando o caso necessita de internação hospitalar. Não aparece aqui o/a Curupira engerado nos órgãos oficiais de saúde, mas a relação é sempre difícil.

A relação entre os ACS e os especialistas locais de cura apresenta-se como complementar, mesmo havendo tensão em algumas ocasiões, quando divergem quanto ao diagnóstico e ao tratamento. Embora se verifique o que parece ser um sistema articulado, as "parcerias" entre eles não são tranquilas, porque cada um possui um estilo pessoal. Cada um tem seu próprio "jeito de trabalhar", dizem. Isto é, cada especialista de cura recria e usa os procedimentos terapêuticos individualmente conforme seu conhecimento, experiência e circunstância. Ou, de acordo com as orientações dos "bichos" que se invocam durante os "trabalhos", como é o caso dos pajés e curadores. Entretanto, há uma negociação na qual o ACS depende e segue a orientação dada pelo pajé ou pelo curador quando este identifica se a doença lhe pertence ou não, mas aquele também quer fazer valer os conhecimentos que adquiriu nos cursos de capacitação. É comum, em caso de emergência, mobilizar, simultaneamente, mais de um especialista local de cura. Isso porque, como explicou uma ACS, "o que um não conhece, outro conhece; o que um faz, outro não faz". Cada um contribui "do seu jeito", inclusive o ACS, para restaurar a saúde do doente. Verifica-se, nessa mobilização de especialistas, a complementaridade de saberes, que ocorre mesmo quando eles não atuam em concomitância. Assim, durante os cuidados de uma pessoa doente, cria-se uma zona de contato entre esses diferentes sistemas (WAWZZYNIAK, 2009, p. 67).

E aqui se torna importante considerar também o último artigo constante do currículo Lattes de Wawzyniak, que diz respeito à internação hospitalar. As tensões e os conflitos continuam, nesse "internamento que ocorre inicialmente em Belterra e Santarém, cidades mais próximas das comunidades onde residem os caboclos ribeirinhos entre os quais realizei a pesquisa" (WAWZYNIAK, 2011, p. 
97-98). A escolha da forma de tratamento é uma decisão que obedece a diversos critérios:

Uma doença é considerada pelos ribeirinhos como "muito alcançada" quando, após um prolongado itinerário terapêutico envolvendo benzimentos, banhos, massagens, defumações e "remédios do mato" ministrados pelos especialistas locais de cura, e depois de consultar o médico da cidade, "bater chapa" (fazer radiografia ou tomografia), fazer exames clínicos, tomar "remédio da farmácia" e injeções, a pessoa não tem a alegria, a disposição e 0 ânimo restabelecidos: uma pessoa com uma "doença alcançada cai no fundo da rede". Quando nem os especialistas locais de cura nem o agente de saúde conseguem diagnosticar a doença ou a consideram uma doença "braba", remetem o paciente a outros especialistas, "curadores mais poderosos", residentes em outras comunidades. Nessas circunstâncias, se a doença for diagnosticada como "alcançada" ou "doença ruim", mas ainda pertencente ao "cigarro" ou à "reza", mas eles se considerarem impotentes, o paciente é encaminhado a outros ainda mais poderosos. Caso a doença seja considerada como "pertencente ao médico", o paciente é encaminhado ao Centro de Saúde ou hospital, nas cidades de Belterra ou Santarém (WAWZYNIAK, 2011, p. 91).

Neste ponto do itinerário terapêutico o sofrimento do doente aumenta, em razão de uma série de incertezas e angústias: medicamentos caros e considerados como próprios para doenças "ruins", exames como tomografia e Raio X, "internação, a falta de complementaridade de modelos terapêuticos na busca da cura, custo oneroso da permanência na cidade, importância da presença e participação dos parentes nos cuidados e o temor em morrer fora do seu 'lugar'". 0 deslocamento para buscar tratamento em lugares cada vez mais distantes é visto como sofrimento e indicativo da gravidade da doença, além de muitos outros ônus, como as despesas maiores pela permanência na cidade, a falta da presença de amigos e parentes próximos e o medo de morrer longe de casa.

No hospital morre-se só, entre estranhos que não respeitam o "sistema tradicional", sem a presença atenciosa dos parentes e sem os ritos preparatórios para a "viagem" que a pessoa "desenganada" fará. Na iminência da morte, o doente deseja ser velado pelos seus, que, reunidos para render-lhe homenagens, fortalecem as relações sociais, os valores, as regras e os costumes. Neste sentido, o hospital é comparado em oposição ao ambiente doméstico. Este sim considerado como lugar socialmente apropriado para 
terminar os dias entre parentes e vizinhos. Assim, é conveniente evitar ser "arrastado", e "entrar" nessa "paragem", cujos "donos" - os "médicos" - têm pleno domínio e com os quais não se pode fazer "acordo" como se faz com os "encantados" ou os "encantes" a fim de obter alguma vantagem na exploração dos recursos naturais. As representações sobre o hospital e a internação hospitalar são socialmente elaboradas a partir do medo em morrer longe dos cuidados proporcionados pelo aconchego doméstico (WAWZYNIAK, 2011, p. 98).

Considerando as diferentes visões cosmológicas de pacientes e profissionais de saúde que atuam nos hospitais e que normalmente os esquemas culturais desses pacientes são desconsiderados e desrespeitados no ambiente hospitalar, isso coloca os ribeirinhos que neles se internam numa situação de grande desconforto. Daí conclui Wawzyniak que esses "esquemas culturais precisam ser considerados e respeitados pelos profissionais de saúde, de modo a aprimorar o acolhimento e tornar os cuidados mais efetivos, sobretudo se se pretende prestar uma atenção em saúde diferenciada para a população ribeirinha” (WAWZYNIAK, 2011, p. 98)

\section{Considerações Finais}

Tentei neste artigo apresentar e discutir as concepções cosmológicas de populações rurais presentes em três mesorregiões distintas da Amazônia que estão relacionadas, como não poderia deixar de ser, à religião e à medicina, tal como praticadas por essas populações. Tenho estudado essas questões há vários anos, sobretudo no nordeste paraense, onde pude conhecê-las mais de perto, inicialmente quando trabalhava no Movimento de Educação de Base (MEB) na então Prelazia do Guamá, com sede na cidade de Bragança e, mais tarde, na microrregião do Salgado, ao desenvolver pesquisa de campo sobre essa temática para elaboração de trabalhos acadêmicos (dissertação e tese de doutorado em antropologia social). Como também orientei trabalhos acadêmicos como professor da Universidade Federal do Pará, dentro dos campos da antropologia da religião e da saúde, a temática nunca esteve ausente de minhas preocupações.

Retomei o tema da religião e da saúde entre populações rurais da Amazônia neste artigo - enfatizando aspectos cosmológicos - pelo estímulo que recebi a partir da leitura de vários artigos de João Valentin Wawzyniak e de sua tese de doutorado (WAWZYNIAK, 2008). 0 que me instigou, sobretudo, foi a maneira 
como essas questões foram tratadas por ele, aproximando a visão de mundo e a compreensão adotada por essas populações do perspectivismo indígena analisado nos trabalhos de Eduardo Viveiros de Castro, como visto acima.

Essa percepção de Wawzyniak decorreu não só de sua competência como pesquisador, mas também, a meu ver, do fato de ter trabalhado no Tapajós (microrregião de Santarém) com populações rurais indígenas e caboclas. E, além disso, de uma tendência mais recente na antropologia brasileira, que tem superado o divórcio há algum tempo existente entre os estudos de antropologia da religião e da saúde e os estudos de etnologia indígena. Enquanto que alguns antropólogos estudiosos da religião e da saúde entre populações rurais e urbanas não indígenas, conhecedores e muito em contato com sociólogos - especialistas também nessa temática -, esqueciam quase totalmente os mesmos temas entre os índios, tal divórcio ocorria de outro lado: etnólogos muitas vezes não conheciam nem citavam os trabalhos de seus colegas que não estudavam as populações indígenas. Havia, é claro, exceções. Durante muitos anos frequentei o GT Religião e Sociedade na ANPOCS e só recentemente encontrei lá etnólogos. Durante muitos anos propus, juntamente com Bartolomeu Tito Figueirôa de Medeiros (que concebeu a ideia) e Miriam Cristina Rabelo, em reuniões de antropólogos (RBA, ABANNE, REA) e de cientistas sociais (CISO) um GT sobre percursos de saúde e curas espirituais, e só recentemente temos recebido propostas de estudos realizados entre populações indígenas.

Ultimamente, porém, e felizmente, isso tem mudado bastante. Essa mudança, de que participou Wawzyniak, certamente tem ligação com a influência de sua orientadora de doutorado na Universidade Federal de São Carlos, Marina Denise Cardoso, cujo interesse acadêmico no campo da antropologia da saúde também está voltado para as populações indígenas. Chamo atenção para este ponto por ser ele sinal de uma forma de amadurecimento que tem ocorrido nos últimos anos na antropologia brasileira. 0 que tem permitido avanços, como 0 representa a obra de João Valentin Wawzyniak, que nos permite a compreensão mais ampla do campo de estudos da antropologia da religião e da saúde, bem como da sociedade brasileira e da própria condição dos habitantes humanos deste planeta.

A resposta à pergunta do título deste artigo é bem óbvia: o perspectivismo indígena não é só indígena, mas é partilhado em grande medida pelas populações rurais não indígenas de muitas áreas da Amazônia. E, para ficar somente na área 
da antropologia da religião e da saúde, é bom enfatizar que essa compreensão é de fundamental importância para políticas e outras ações no campo da saúde pública. Sem ela continuaremos a ter propostas e ações de saúde desvinculadas da realidade social e entendidas a partir de concepções cosmológicas ou visões de mundo completamente dissociadas das cosmologias e do ethos das populações rurais da Amazônia - para ficar só nelas -, o que constitui sério entrave a sua eficácia e efetividade. Não creio, porém, que seja demais remeter também o leitor - nesta conclusão - ao artigo de Dominique Buchillet (2000) que aborda ações de saúde no tratamento de tuberculose entre populações indígenas brasileiras, onde essas questões são vivamente retratadas.

\section{REFERÊNCIAS}

BUCHILLET, Dominique. Tuberculose, cultura e saúde pública. Brasília: DAN, 2000. Disponível em: <www.unb.br/ics/dan/serie20empdf.pdf>. Acesso em: 19 mar. 2012.

CASTR0, Eduardo Viveiros de. Cosmological deixis and amerindian perspectivism. The Journal of the Royal Anthropological Institute, London, v. 4, n. 3, p. 469-488, 1998.

CAVALCANTE, Patrícia Carvalho. De nascença ou de simpatia: iniciação, hierarquia e atribuições dos mestres na pajelança marajoara. 2008. Dissertação (Mestrado em Ciências Sociais). Universidade Federal da Pará, Belém. Disponível em: $\quad<$ http://www.ppgcs.ufpa.br/arquivos/dissertacoes/dissertacaoTurma2006PatriciaCavalcante.pdf>. Acesso em: 19 mar. 2012.

CRAVALHO, Mark. An invisible universe of evil: supernatural malevolence and personal experience among Amazon peasants. 1993. Dissertação (Doutorado em Antropologia) - University of Califórnia, San Diego.

De doente a "encantado": o conceito de mecanismo de defesa constituído culturalmente e a experiência de uma vítima de 'espírito mau' em uma comunidade rural na Amazônia. In: ALVES, Paulo César; RABELO, Mirian Cristina (Org.). Antropologia da saúde: traçando identidades e explorando fronteiras. Rio de Janeiro: Relume Dumará, 1998. p. 155-177.

ELIADE, Mircea. O sagrado e o profano: a essência das religiões. Lisboa: Livros do Brasil, 1957. 
O xamanismo e as técnicas arcaicas do êxtase. São Paulo: Martins Fontes, 2002.

EVANS-PRITCHARD, Edward Evan. Witchcraft, oracles and magic among the azande. Oxford: Clarendon Press, 1937.

FIGUEIRED0, Aldrin Moura de. A cidade dos encantados: pajelanças, feitiçarias e religiões afro-brasileiras na Amazônia, 1870-1950. Belém: Edufpa, 2009.

FIGUEIREDO, Napoleão. Os "bichos" que curam: os animais e a medicina de 'folk' em Belém do Pará. Boletim do Museu Paraense Emilio Goeldi, Série Antropologia, Belém, v. 10, n. 1, p. 75-91, 1994.

- Pajelança e catimbó na região Bragantina. Revista do Instituto Histórico e Geográfico de Alagoas, Maceió, v. 32, p. 41-52, 1976.

Rezadores, Pajés \& Puçangas. Belém: UFPA, 1979.

FIGUEIREDO, Napoleão; SILVA, Anaiza Vergolino. Festas de santos e encantados. Belém: Academia Paraense de Letras, 1972.

GALVÃ0, Eduardo. Santos e visagens: um estudo da vida religiosa de Itá, Baixo Amazonas. São Paulo: Nacional, 1955.

HARRIS, Mark. Life on the Amazon: the anthropology of a Brazilian Peasant Village. Oxford: The Oxford University Press, 2000.

. Presente ambivalente: uma maneira amazônica de estar no tempo. In: MURRIETA, Rui; ADAMS, Cristina; NEVES, Walter (Org.): Sociedades caboclas amazônicas: modernidade e invisibilidade. São Paulo: Annablume, 2006. p. 81108.

LÉVI-STRAUSS, Claude. O pensamento selvagem. São Paulo: Nacional, 1970.

LIMA AYRES, Déborah de Magalhães. A construção histórica da categoria caboclo: sobre estruturas e representações sociais no meio rural. Novos Cadernos NAEA, Belém, v. 2, n. 2, p. 5-32, 1999. Disponível em: < http://www.periodicos.ufpa.br/ index.php/ncn/article/view/107/161>. Acesso em: 19 mar. 2012.

. The social category caboclo: history, identity and outsider's social classification of a rural population of the Amazon Middle Solimões River. 1992. Tese (Doutorado em Antropologia) - University of Cambridge, Cambridge.

MARTINS, José de Souza. 0 tempo da fronteira: retorno à controvérsia sobre 0 tempo histórico da frente de expansão e da frente pioneira. Tempo Social, São 
Paulo, v. 8, n. 1, p. 25-70, 1996. Disponível em: <http://www.fflch.usp.br/ sociologia/temposocial/pdf/vol08n1/0\%20tempo.pdf> . Acesso em: 19 mar. 2012. . Os camponeses e a política no Brasil. Petrópolis: Vozes, 1981.

MARTON, Scarlett. Nietzsche: das forças cósmicas aos valores humanos. Belo Horizonte: UFMG, 2000.

MAUÉS, Raymundo Heraldo. A ilha encantada: medicina e xamanismo numa comunidade de pescadores. 1977. Dissertação (Mestrado em Antropologia) Universidade de Brasília, Brasília.

. A ilha encantada: medicina e xamanismo numa comunidade de pescadores. Belém: UFPA, 1990.

. 0 simbolismo e o boto na Amazônia: religiosidade, religião, identidade. História Oral, Rio de Janeiro, v. 9, n. 1, p. 11-28, 2008.

- Padres, pajés, santos e festas: catolicismo popular e controle eclesiástico. Belém: CEJUP, 1995.

MAUÉS, Raymundo Heraldo; VILLACORTA, Gisela Macambira. Pajelança e encantaria amazônica. In: PRANDI, Reginaldo (Org.). Encantaria brasileira: o livro dos mestres, caboclos e encantados. Rio de Janeiro: Pallas, 2001. p. 11-58.

MOTT, Luis. Etnodemonologia: a vida sexual do Diabo no mundo ibero-americano. Religião e Sociedade, Rio de Janeiro, v. 12, n. 2, p. 64-99, 1985.

MOTTA-MAUÉS, Maria Angélica. A questão étnica: índios, brancos, negros e caboclos. In: LOUREIR0, Violeta R. (Org.). Estudos e problemas Amazônicos. Belém: IDESP/SEDUC, 1989. p. 196-204.

MURRIETA, Rui S. S. Dialética do sabor: alimentação, ecologia e vida cotidiana em comunidades ribeirinhas da ilha de Ituqui, baixo Amazonas, Pará. Revista de Antropologia, São Paulo, v. 44, n. 2, p. 39-88, 2001.

. 0 dilema do papa-chibé: consumo alimentar, nutrição e práticas de intervenção na Ilha de Ituqui, Baixo Amazonas, Pará. Revista de Antropologia, São Paulo, v. 41, n. 1, p. 97-145, 1998.

MUSUMECI, Leonarda. O mito da terra liberta (colonização "espontânea", campesinato e patronagem na Amazônia Oriental): ANPOCS/Vértice. São Paulo: Revista dos Tribunais, 1988.

NIETZSCHE, Frederico. A gaia ciência. Lisboa: Guimarães, 2000. 
NOVAES, Regina Reys. De corpo e alma: catolicismo, classes sociais e conflitos no campo. Rio de Janeiro: Graphia, 1997.

. Os escolbidos de Deus: pentecostais, trabalhadores \& cidadania. Rio de Janeiro: ISER/Marco Zero, 1985. (Cadernos do ISER 19).

QUINTAS, Gianno Gonçalves. Entre maracás, curimbas e tambores: pajelanças nas religiões afro-brasileiras. 2007. Dissertação (Mestrado em Ciências Sociais). Universidade Federal do Pará, Belém. Disponível em: <http:/www.ppgcs.ufpa.br/ arquivos/dissertacoes/dissertacaoTurma2005-GiannoQuintas.pdf> . Acesso em: 19 mar. 2012.

RODRIGUES, Carmem Izabel. Caboclos na Amazônia: a identidade na diferença. Novos Cadernos NAEA, Belém, v. 9, n. 1, p. 119-130, 2006. Disponível em: <http:// www.periodicos.ufpa.br/index.php/ncn/article/view/60/131>. Acesso em: 19 mar. 2012.

SALLES, Vicente. Cachaça, pena e maracá. Brasil Açucareiro, Rio de Janeiro, v. 27, n. 74, p. 46-55, 1967.

SIGAUD, Lygia. Os clandestinos e os direitos. São Paulo: Duas Cidades, 1979.

SILVA, Andréa L. Comida de gente: preferências e tabus alimentares entre os ribeirinhos do Médio Rio Negro (Amazonas, Brasil). Revista de Antropologia, São Paulo, v. 50, n. 1, p. 125-179, 2007.

SILVA, Maria Ivonete Coutinho. Mulheres migrantes na transamazônica: construção da ocupação e do fazer política. 2008. Tese (Doutorado em Ciências Sociais) - Universidade Federal do Pará, Belém. Disponível em: <http://www. ppgcs.ufpa.br/arquivos/teses/teseTurma2004-MariaSilva.pdf>. Acesso em: 26 out. 2010.

SILVA, Tatiana Lins. Os curupira foram embora: economia, política e ideologia numa comunidade amazônica. 1980. Dissertação (Mestrado) - Universidade Federal do Rio de Janeiro, Rio de Janeiro.

SLATER, Candace. Dance of the dolphin: transformation and disenchantment in the Amazonian imagination. Chicago: The University of Chicago Press, 1994.

SMITH, Nigel. Man, Fishes, and the Amazon. Gainesville: Florida University Press, 1982.

SOARES, José Arlindo. A frente do Recife e o governo de Arraes. Rio de Janeiro: Paz e Terra, 1982. 
TRINDADE, Raida Renata Reis. Aqui a cura é de verdade: reflexões em torno da cura xamânica em São Caetano de Odivelas-PA. 2007. Dissertação (Mestrado em Ciências Sociais) - Universidade Federal do Pará, Belém. Disponível em: < http:// www.ppgcs.ufpa.br/arquivos/dissertacoes/dissertacaoTurma2005-RaidaTrindade. pdf>. Acesso em: 19 mar. 2012.

VELHO, Otávio. Besta-Fera: recriação do Mundo. Rio de Janeiro: Relume-Dumará, 1995.

. Frentes de expansão e estrutura agrária. Rio de Janeiro: Zahar, 1981. WAGLEY, Charles. Uma comunidade Amazônica. São Paulo: Nacional, 1977. WAWZYNIAK, João Valentin. "Engerar" uma categoria cosmológica sobre pessoa, saúde e corpo. Ilha, Florianópolis, v. 5, n. 2, p. 33-55, 2003. Disponível em: <www. periodicos.ufsc.br/index.php/ilha/article/download/.../15348>. Acesso em: 19 mar. 2012.

. Agentes comunitários de saúde: transitando e atuando entre diferentes racionalidades no rio Tapajós, Pará, Brasil. Campos, Curitiba, v. 10, n. 2, p. 5981, 2009. Disponível em: <http://ojs.c3sl.ufpr.br/ojs2/index.php/campos/article/ view/20164/13421>. Acesso em: 19 mar. 2012.

Assombro de olhado de bicho: uma etnografia das concepções e ações em saúde entre os ribeirinhos do baixo Tapajós, Pará - Brasil. 2008. Tese (Doutorado em Ciências Sociais) - Universidade Federal de São Carlos, São Carlos. Disponível em: <http://www.bdtd.ufscar.br/htdocs/tedeSimplificado/tde_ arquivos/6/TDE-2009-07-07T090524Z-2145/Publico/2147.pdf>. Acesso em: 19 mar. 2012.

. Curupira engerado em IBAMA: apreensão de um órgão público federal em termos cosmológicos locais". Teoria \& Pesquisa, São Carlos, v. 44/45, p. 5-18, 2004.

. Humanos e não-humanos no universo transformacional dos ribeirinhos do rio Tapajós - Pará. In: REUNĨ̃o BRASILEIRA DE ANTROPOLOGIA, 27., 2010, Belém. Anais... Belém, 2010. Disponível em: < http://www.abant.org.br/conteudo/ ANAIS/CD_Virtual_27_RBA/arquivos/grupos_trabalho/gt24/jww.pdf >. Acesso em: 19 mar. 2012.

. Percepção da internação e do ambiente hospitalar por ribeirinhos do Tapajós, Pará, Brasil. Revista Tempus Actas de Saúde Coletiva, Brasília, v. 5, n. 
2, p. 89-104, 2011. Disponível em: <http://www.tempusactas.unb.br/index.php/ tempus/article/viewFile/966/908 > . Acesso em: 19 mar. 2012.

WOORTMANN, Klaas. Hábitos e ideologias alimentares em grupos sociais de baixa renda: relatório final. Brasília: DAN, 1978. Disponível em: <http://www. dan.unb.br/doc/Serie20empdf.pdf>. Acesso em: 19 mar. 2012. 